\title{
An Experimental Study of the Effects of Nicotine on the Intervertebral Disc
}

\author{
Nahla M. Afifi**\# and Kawther A. Hafez** \\ **Department of Anatomy, Faculty of Medicine, Ain Shams University \\ \#Health Sciences Department, College of Arts \& Sciences, Qatar University
}

\begin{abstract}
Backgrounds: Clinically it had been noticed that a large proportion of patients presenting with low back pain are smokers. Therefore, in this experimental study the histological effects of nicotine on the lumbar intervertebral discs of the rabbits was investigated.

Material and Methods: Eighteen rabbits were divided equally into 3 groups, Group 1 (a \& b); as control. Group2 injected intraperitoneally by $5000 \mathrm{ng} / \mathrm{kg}$ nicotine daily for 4 weeks. Group3 injected intraperitoneally by $5000 \mathrm{ng} / \mathrm{kg}$ nicotine daily for 8 weeks. The selected dose produced blood nicotine levels equivalent to those found in heavy smokers (30 cigarettes / day).

Results: Light and electron microscopic studies revealed that nicotine injection showed a variety of histological changes, which were not observed in the control group. This includes appearance of spaces within the nucleus pulposus and separation from the adjacent fibrous lamellae in the annulus fibrosus. Also loss of the regularity of the multilayered structure of the annulus fibrosus, and excessive inclusions associated with vacuoles which continue with the rough endoplasmic reticulum within the chondrocytes. Disc degeneration was more marked in rabbits injected with nicotine for 8 weeks (G3) than in those injected for 4 weeks (G2).

Conclusion: It could be concluded that the disc degeneration is more common among smokers and is correlated with the duration of exposure to nicotine.
\end{abstract}

\section{Introduction}

The harmful effects of tobacco smoking had been studied in every field of medicine. Epidemiological studies over the past few decades had demonstrated an association between smoking and back pain (Scott et al., 1999).

The intervertebral discs are an integral part of the vertebral column and are essential for maintaining stability and alignment by anchoring adjacent vertebral bodies. They allow the vertebral column to absorb energy and distribute loads applied through the axial skeleton (Antoniou et al., 1996).

The intervertebral disc consists of a resident cell population, extracellular matrix consisting of a framework of macromolecules and water. The proportion and composition of these various components may vary in different regions of the intervertebral disc. The nucleus pulposus consists of a gelatinous matrix composed of high concentrations of proteoglycans, type II collagen, and water
(70\%-80\%). The interconnecting notochordal cells at birth are later replaced by chondrocyte-like cells (Iatridis et al., 1996). Intervertebral disc degeneration is thought to be a major factor responsible for back pain (Buckwalter 1995). Mechanisms for the association of back pain and smoking are poorly understood but carboxy-hemoglobin production, vasoconstriction (Miller et al., 2000), arteriosclerotic vessel wall changes, impaired fibrinolytic activity, and changes in blood flow (Ernst 1994) have all been proposed as mediators of malnutrition in the intervertebral disc.

Nicotine is a major contributor to the physical addiction associated with cigarette smoking (Lawson et al., 1997). It enters the systemic circulation and diffuses freely through capillaries into extravascular spaces and in its free form is distributed rapidly to most body tissues (Rang et al., 2003). It is likely that nicotine enters the intervertebral disc through peripheral capillaries and then 
by diffusion into the nucleus pulposus in a similar manner to other nutrients (Akmal et al., 2004).

The incidence of smoking among young adults is increasing, particularly in the developing countries and back pain is a major contributor of disability and loss of productivity in the workforce (Abenhaim \& Sussia 1987).

Accordingly it was the aim of the present work to investigate the effect of nicotine on the different parts of the lumbar intervertebral discs of the adult male Balady rabbits and to detect the relation between the duration of exposure to nicotine and its effects on the lumbar intervertebral discs.

\section{Material and Methods}

In this study 18 adult male Balady rabbits weighing $1000-1200$ gm were used. They were divided into 3 groups of 6 rabbits each.

Group 1(a \& b): The control group received $0.5 \mathrm{ml} / \mathrm{kg}$ saline intrapertonially daily for 4 and 8 weeks successively.

Group 2: The rabbits received $5000 \mathrm{ng} / \mathrm{kg}$ nicotine solution intrapertonially daily for 4 weeks.

Group 3: The rabbits received $5000 \mathrm{ng} / \mathrm{kg}$ nicotine solution intrapertonially daily for 8 weeks.

Nicotine alkaloid solution was obtained from SIGMA Company. The concentration of nicotine was $100 \mathrm{ng} / \mathrm{ul}$. Dilutions were prepared with final concentration of $10000 \mathrm{ng} / \mathrm{ml}$ normal saline. This solution was stored in a sealed, opaque glass container under refrigeration to minimize oxidation.

Food and water were allowed ed libitum. Rabbits were weighed every second week, and doses were adjusted.

The selection of the dose for the nicotine was based on the study of Uematsu et al., (2001) who indicated that this level will achieve a blood level concentration around $110 \mathrm{ng} / \mathrm{ml}$. This level was equivalent to the mean concentration determined 1 hour or more after smoking in 10 smokers who smoked daily 30-40 cigarettes containing $0.5 \mathrm{mg}$ of nicotine each.

At time of sacrification the whole vertebral column was fixed in $10 \%$ neutral buffered formalin then decalcified in $10 \%$ EDTA 'ethylenediamine tetraacetic acid sodium salt.' Then the lumbar region is processed for light microscopic examination. Sections were cut 5 um in thickness and stained with haematoxylin and eosin and examined under light microscope.

For electron microscopic study specimens were fixed immediately in $3 \%$ glutaraldehyde in 0.1 phosphate buffer, and decalcified in $10 \%$ EDTA. In the thoroughly decalcified specimen the lumber intervertebral discs were identified under the stereomicroscope then processed and embedded in Epoxy resin. Ultrathin sections were cut and stained with uranyl acetate and lead citrate. They were examined and photographed by Philips 400 Transmission Electron Microscope.

\section{Results}

\section{Group 1 a \&b (control):}

The intervertebral disc was formed of two parts, the nucleus pulposus and the annulus fibrosus. The cells of nucleus pulposus were scattered in irregular clumps throughout an extracellular matrix which consisted of ground substance only (Fig. 1). Histologically, the fibrocartilage of the annulus fibrosus appeared as small fields of cartilage blending almost imperceptibly with regions of fibrous tissue. No perichondrium was present. The $\mathrm{H} \& \mathrm{E}$ stained slides viewed that the tissue had a fibrous appearance and the nuclei of the fibroblasts appeared as small, elongated or spindle shaped bodies. There were relatively few fibroblasts present as is characteristic of the dense connective tissue (Fig 2). The cartilage cells (chondrocytes) were more numerous; some of them appeared as elongated clusters of cells, whereas others appeared in single file rows. They were contained within lacunae. The matrix contained thick bundles of collagen fibers which were arranged in a more or 
less regular fashion between the rows of cartilage cells (Fig 3).

Under the electron microscope the chondrocytes appeared as a cluster of cells. The nuclei of the chondrocytes mostly were eccentrically located and the cytoplasm displays mitochondria and numerous, extensive rough endoplasmic reticulum (Fig 4). Glycogen granules were scattered in the cytoplasm. It was noticed that the outer surface of the chondrocyte appeared as ruffled appearance, and all chondrocytes were completely filling their lacuna within the matrix (Fig 5).

The fibroblasts exhibit long cytoplasmic processes that pass between the collagen bundles. The processes extended for indeterminate distances and became attenuated. The nucleus was moderately condensed and the nucleoli were not a prominent feature. The cytoplasm showed conspicuous profiles of rough endoplasmic reticulum. Surrounding the cells were bundles of collagen fibrils in transverse and longitudinal section in extracellular matrix (Fig 6).

\section{Group 2 (four weeks treated group):}

Sections of the intervertebral disc stained with H\&E showed signs of degeneration. The nucleus pulposus contained small spaces with separation from the adjacent annulus fibrosus (Fig 7). The regularity of the multilayered structure of the annulus fibrosus was disturbed with separation of adjacent lamellae and appearance of small cracks (Figs. 8, 9).

Electron microscopic examination showed that the chondrocytes had numerous rough endoplasmic reticulum and intact mitochondria with the appearance of dilated vacuoles which indented the nucleus (Figs 10, 11). The fibroblast showed no pathological changes, but there is disturbance of the arrangement and loss of the surrounding collagen fibers in the surrounding areas (Fig 12).

\section{Group 3 (eight weeks treated group):}

In eight week treated nicotine group (group 3), the progression of degeneration of the disc was evident. The small spaces have expanded in wide areas of the nucleus pulposus with wide separation from the adjacent annulus fibrosus (Fig 13). The irregularity of the multilayered structure of the annulus fibrosus has progressed further, with marked separation of adjacent fibrous lamellae, interruption and cracks (Figs 14, 15).

Electron microscopic examination revealed that, there were extensive vacuoles with many inclusion bodies and electron dense spots in the cytoplasm of the chondrocytes and some nuclei appeared condensed with corrugated nuclear membranes (Figs 16, 17). Some nuclei of the fibroblast showed corrugated nuclear membranes and there was extensive loss of the surrounding collagen fibers. (Fig 18). 


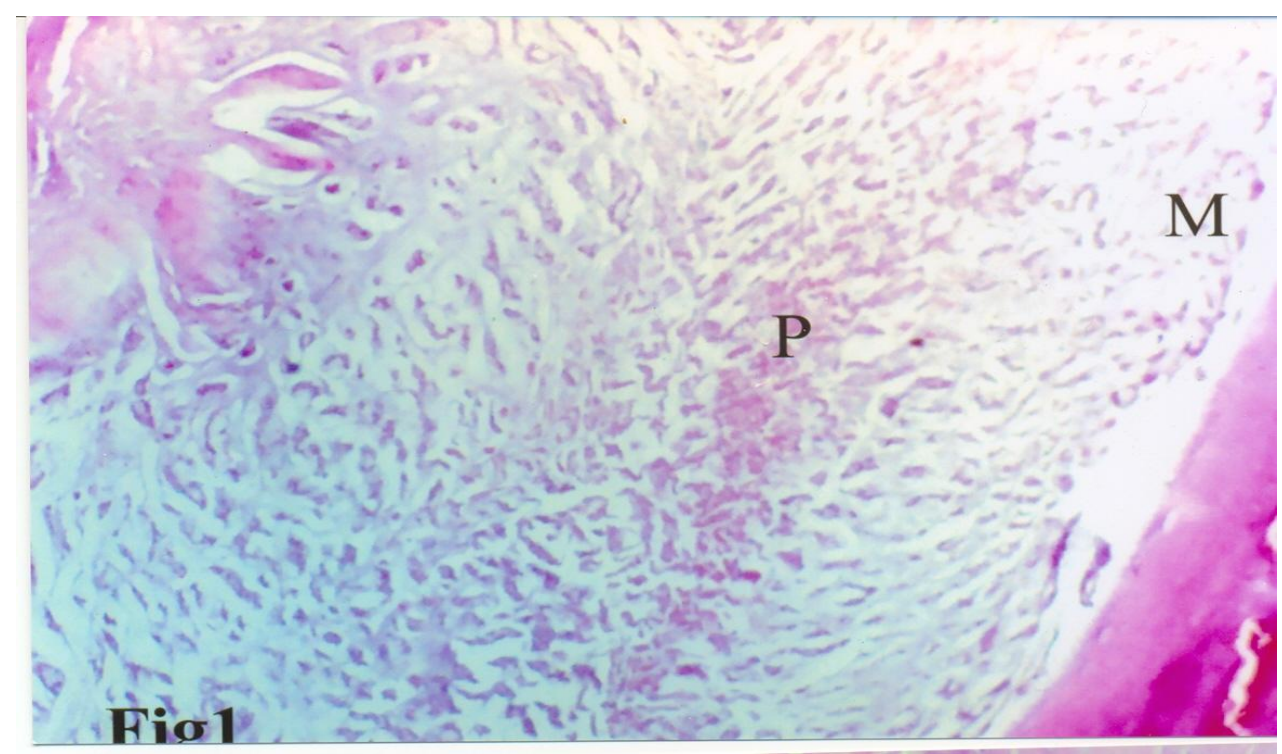

Fig (1): Photomicrograph of a section of intervertebral disc at lumbar region of a control group, showing the well maintained nucleus pulposus surrounded by annulus fibrosus. The cells of nucleus pulposus (P) are scattered in irregular clumps throughout an extracellular matrix $(M)$ which consists of ground substance only.

(H \& E x 100)

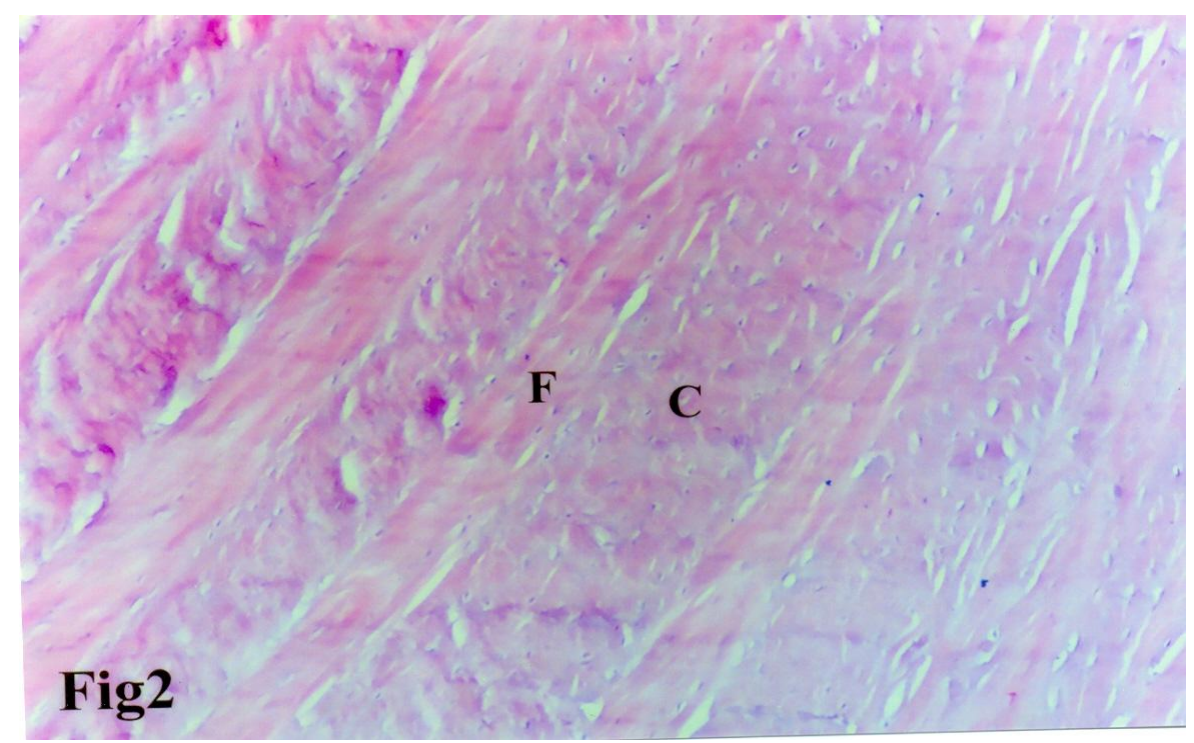

Fig (2): Photomicrograph of a section of intervertebral disc at lumbar region of a control group showing the fibrocartilage of the annulus fibrosus. It appears as small fields of cartilage $(C)$ blending almost imperceptibly with regions of fibrous tissue $(F)$. No perichondrium is present.

(H\&E x 100) 


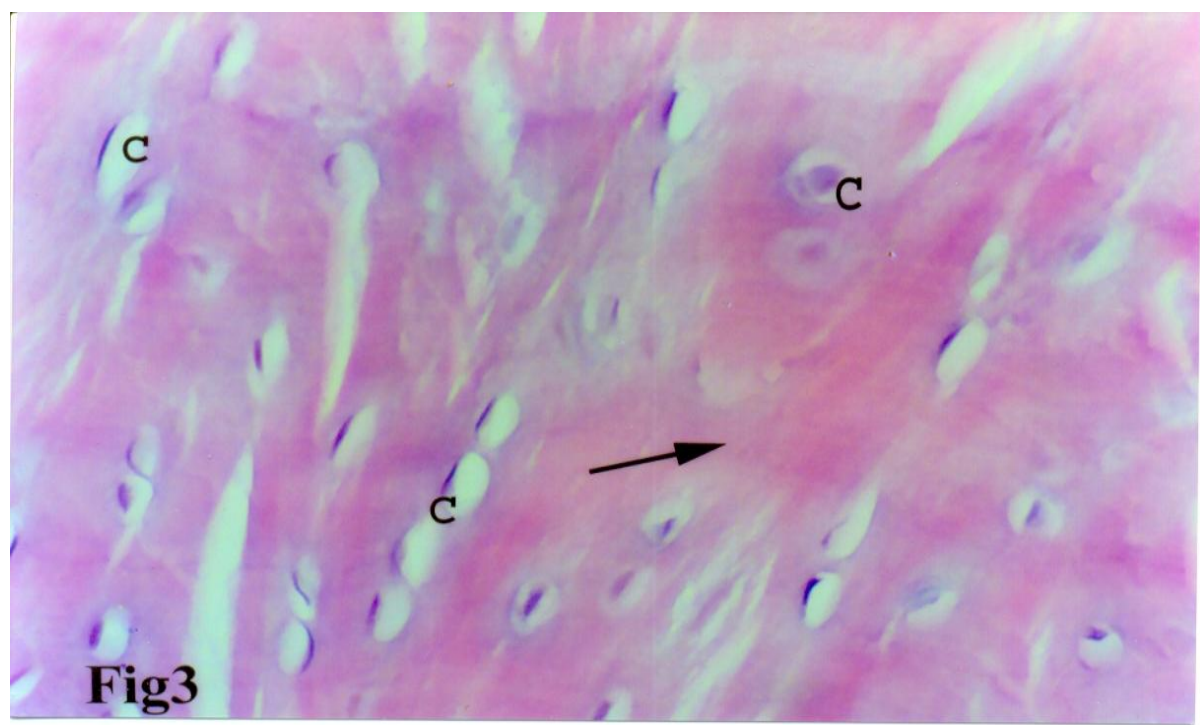

Fig (3): Photomicrograph of a section of the annulus fibrosus of intervertebral disc at lumbar region of a control group showing the numerous cartilage cells $(C)$ where they appeared as elongated clusters of cells and were contained with in lacunae. The matrix contained thick bundles of collagen fibers which were arranged in a more or less regular fashion $(\rightarrow \rightarrow \quad$ ( H\&E x 400)

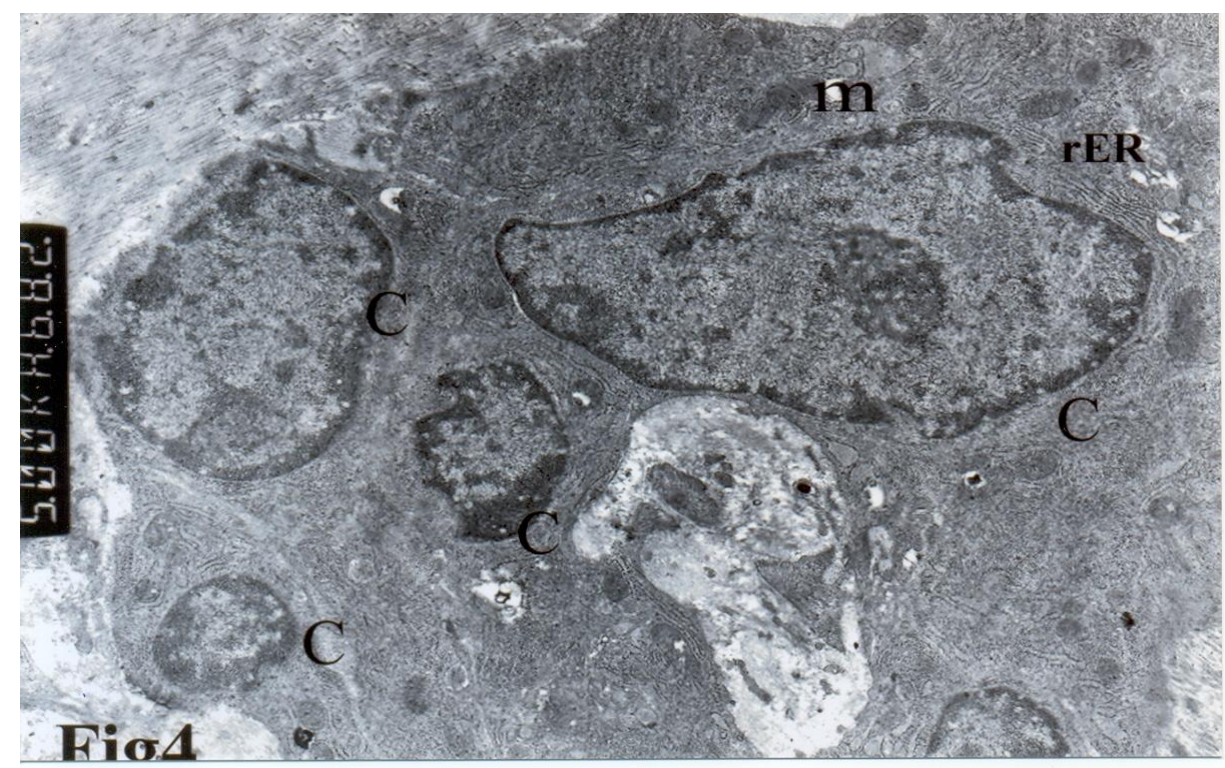

Fig (4): Electron micrograph of a section of intervertebral disc at lumbar region of a control group showing a cluster of chondrocytes (C). The cytoplasm displays mitochondria (m) and numerous rough endoplasmic reticulum (rER ).

( Uranyl acetate \& Lead citrate x 5000) 


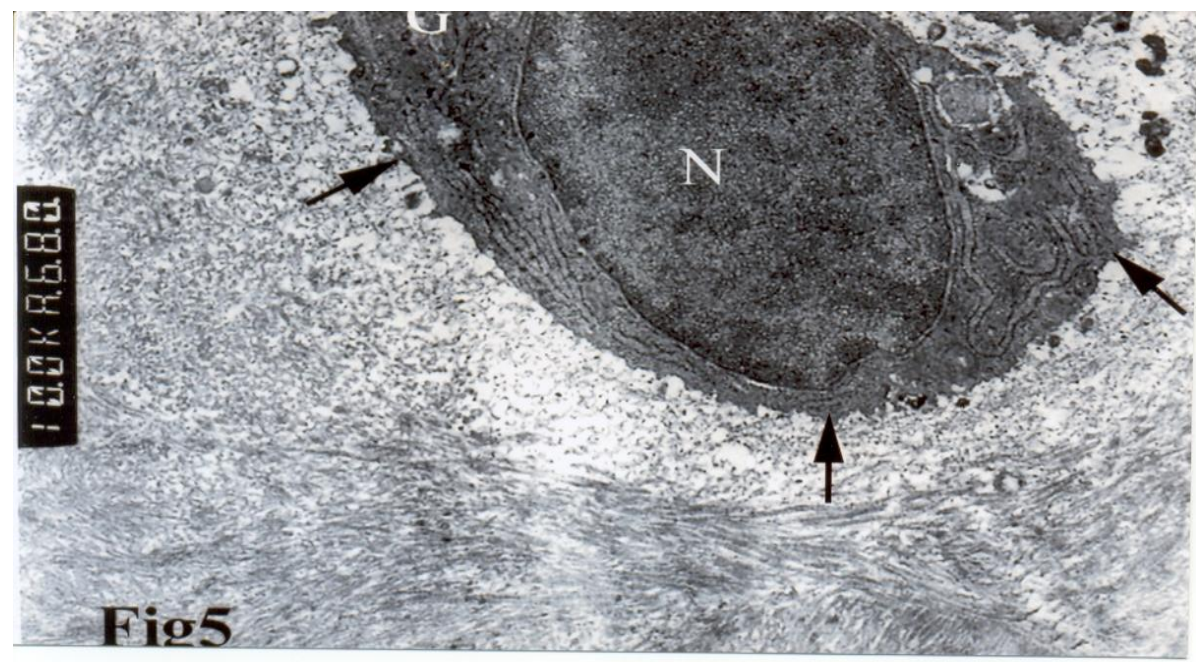

Fig (5): Electron micrograph of a section of intervertebral disc at lumbar region of a control group showing the eccentric located nucleus $(N)$. Glycogen granules were scattered in the cytoplasm (G). Notice, the outer surface of the chondrocyte appeared as ruffled appearance ( $\quad$ $*$ Uranyl acetate \& Lead citrate $x$ 10000)

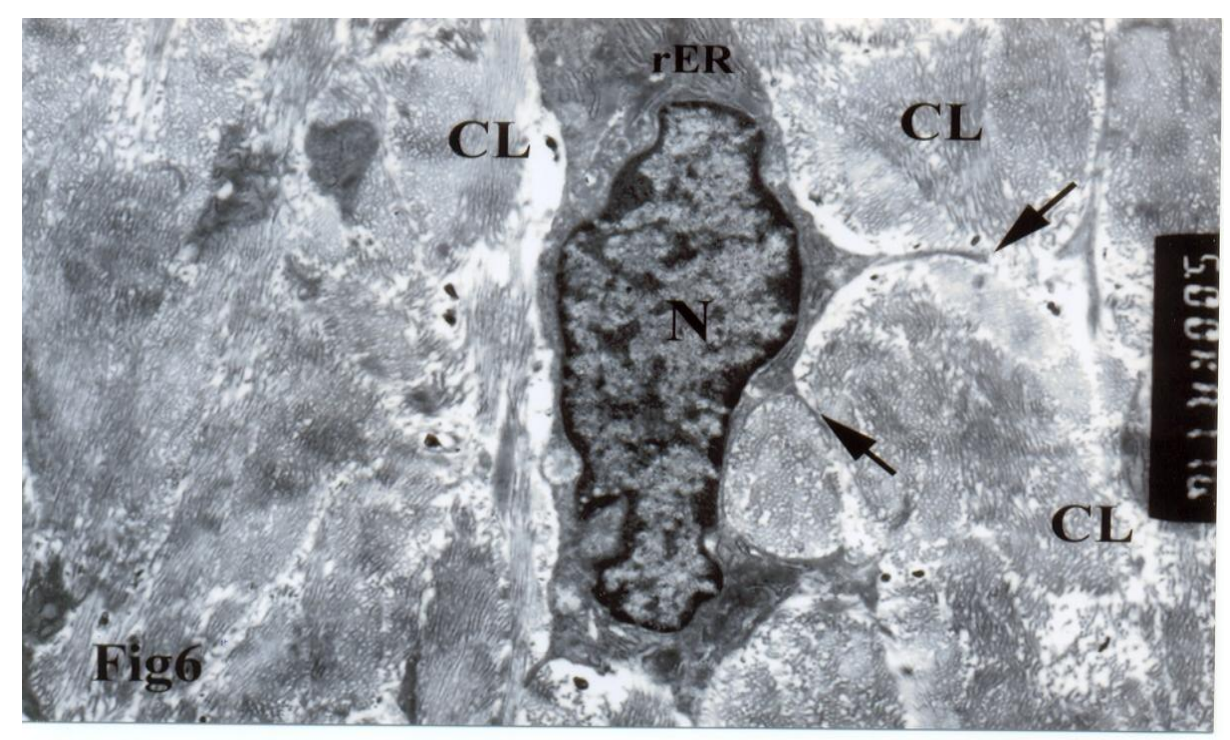

Fig (6): Electron micrograph of a section of intervertebral disc at lumbar region of a control group showing fibroblast with long cytoplasmic processes that pass between the collagen bundles $(\longrightarrow)$, moderately condensed nucleus $(N)$ and conspicuous profiles of rough endoplasmic reticulum (rER). Surrounding the cells were bundles of collagen fibrils in transverse and longitudinal section in extracellular matrix $(\mathrm{CL})$.

( Uranyl acetate \& Lead citrate $\mathrm{x}$ 5000) 


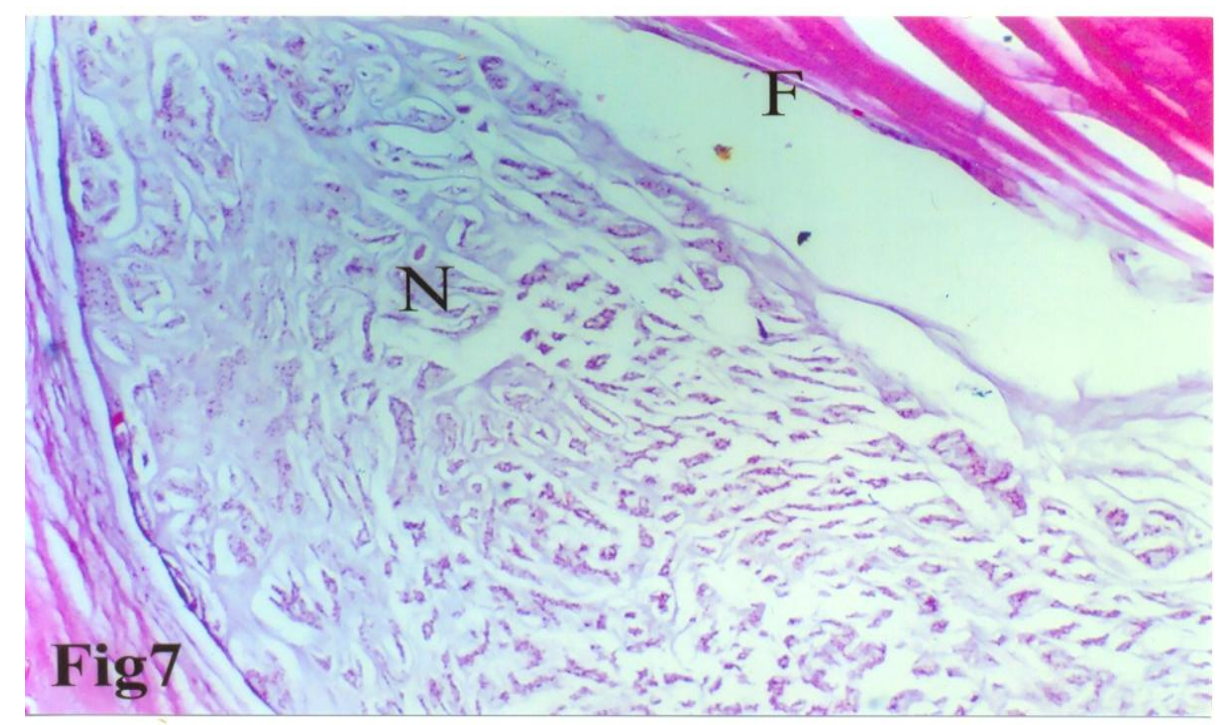

Fig (7): Photomicrograph of a section of intervertebral disc at lumbar region of four weeks nicotine group (group 2) showing degeneration $(\rightarrow)$ of the nucleus pulposus which contains small spaces $(\mathrm{N})$ and separation of the adjacent fibrous lamellae in the annulus fibrosus (F).

(H \& E x 100)

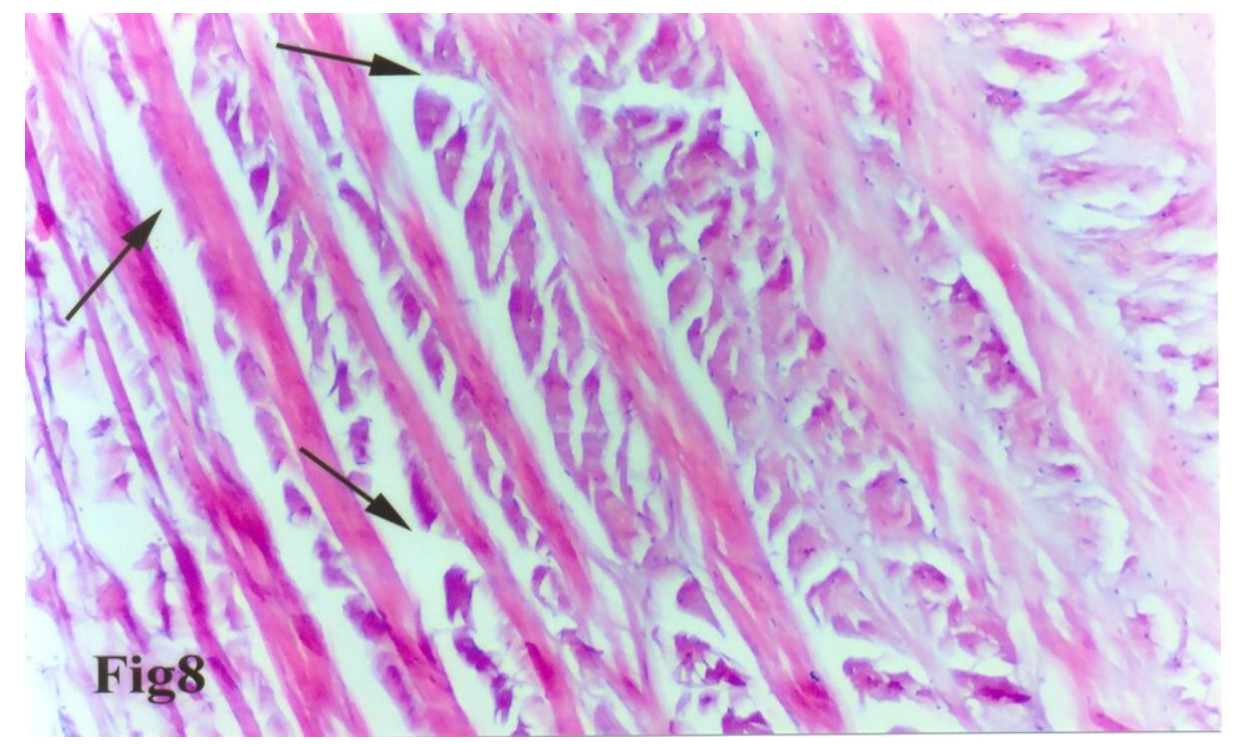

Fig (8): Photomicrograph of a section of intervertebral disc at lumbar region of four weeks nicotine group (group 2) showing disturbed regularity of the multilayered

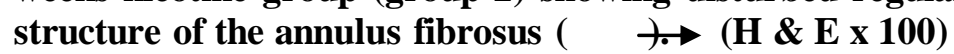




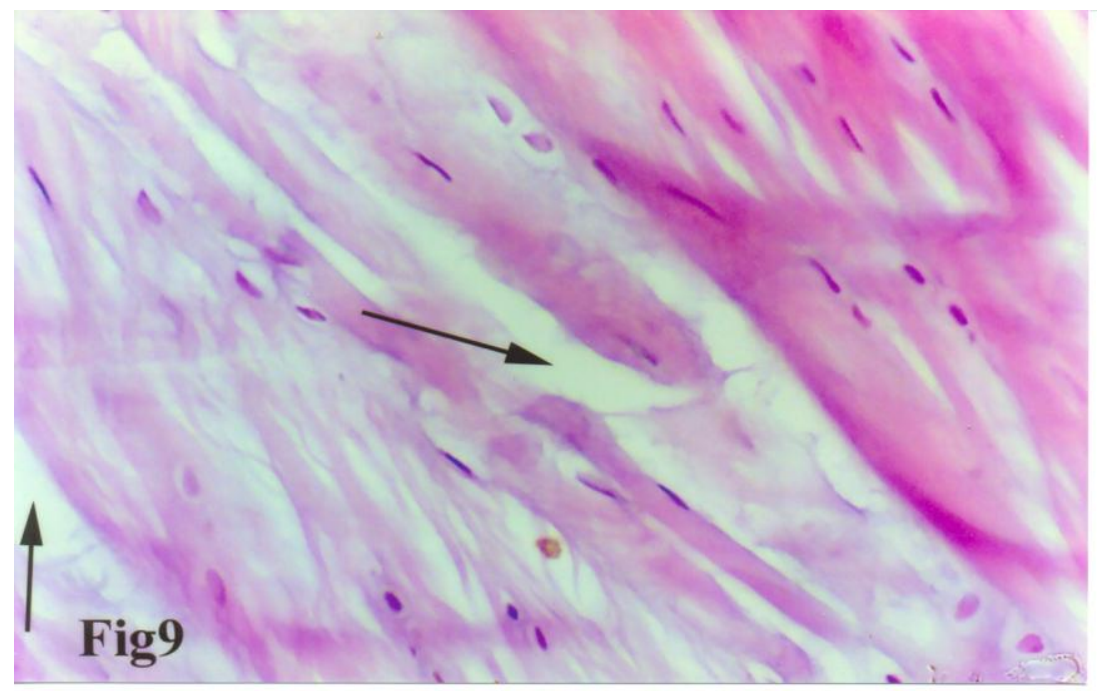

Fig (9): Photomicrograph of a section of intervertebral disc at lumbar region of four weeks nicotine group (group 2) showing separation of the adjacent lamellae and appearance of small cracks within the annulus fibrosus ( ).

$(H \&$ E $x$ 400)

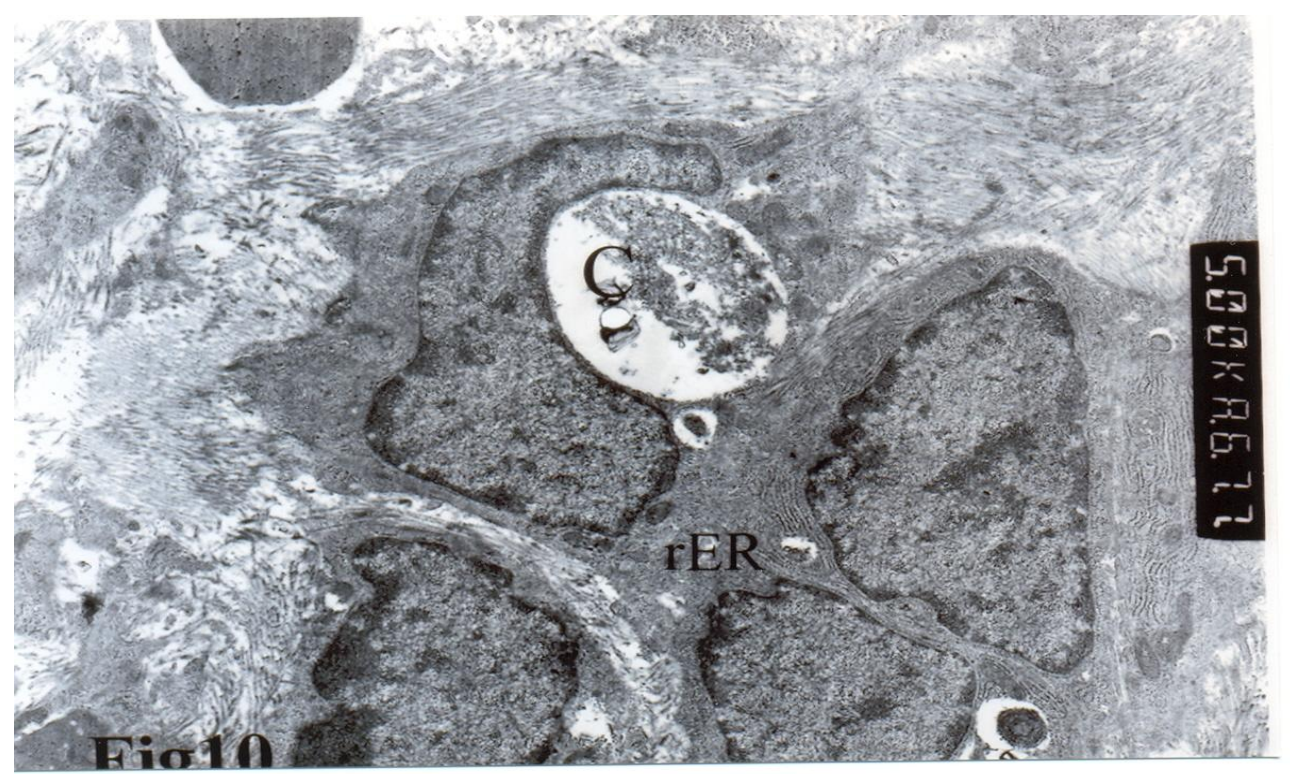

Fig (10): Electron micrograph of a section of intervertebral disc at lumbar region of four weeks nicotine group (group 2) showing chondrocytes with extensive rough endoplasmic reticulum (rER) and a dilated vacuole which indenting the nucleus (C).

( Uranyl acetate \& Lead citrate $x$ 5000) 


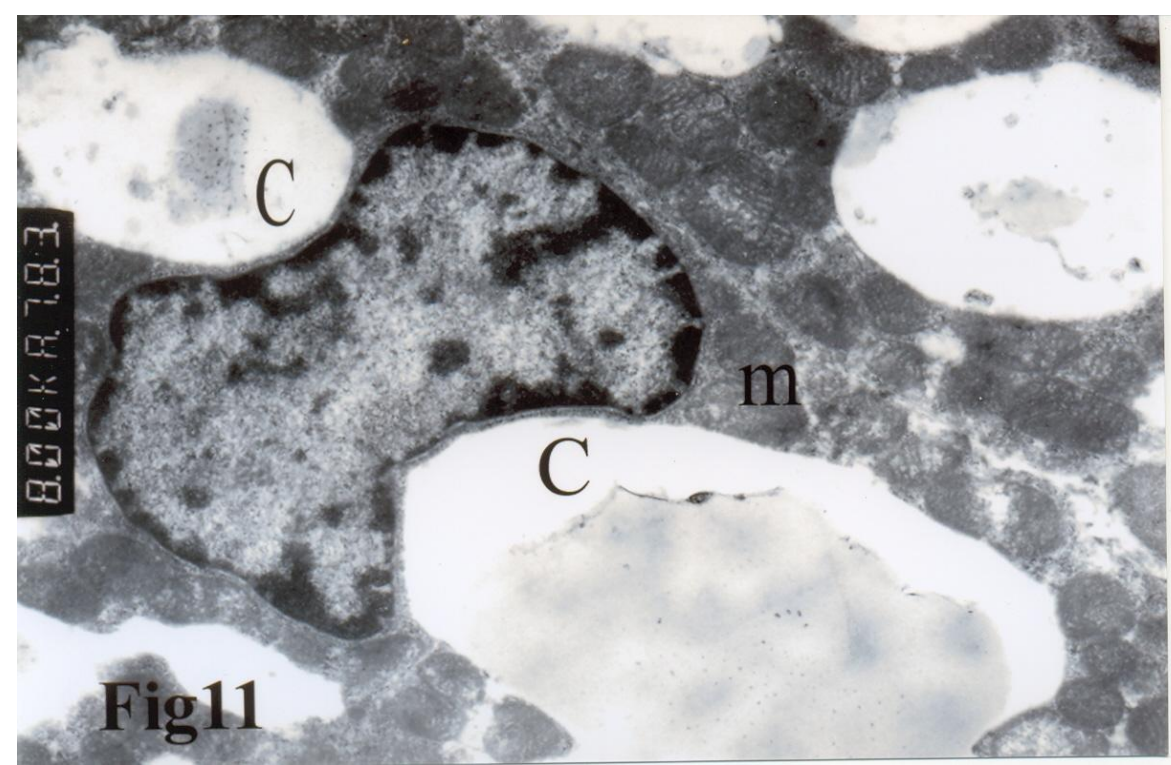

Fig (11): Electron micrograph of a section of intervertebral disc at lumbar region of four weeks nicotine group (group 2) showing chondrocytes with dilated vacuoles which indenting the nucleus $(\mathrm{C})$ and intact mitochondria (m).

( Uranyl acetate \& Lead citrate $x$ 10000)

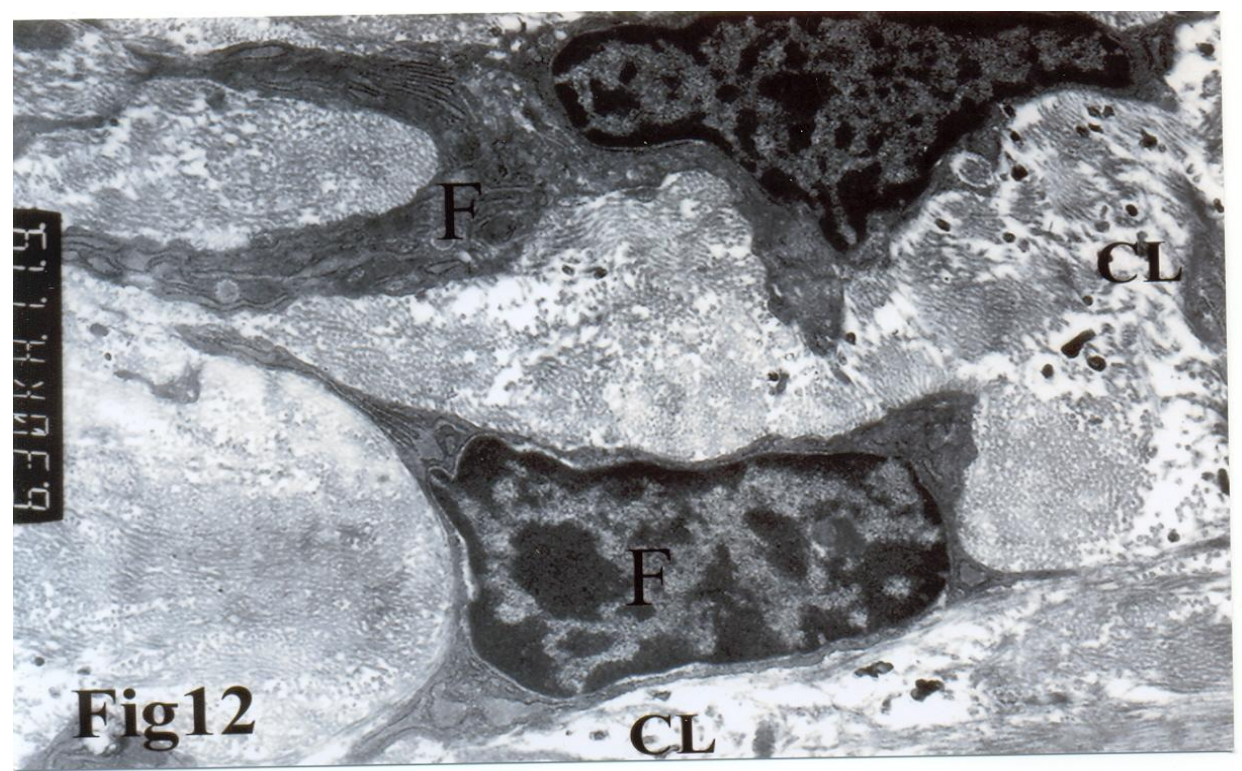

Fig (12): Electron micrograph of a section of intervertebral disc at lumbar region of four weeks nicotine group (group 2) showing no pathological changes in the fibroblast (F), but there is disturbance in the arrangement and loss of the surrounding collagen fibers in the surrounding areas $(\mathrm{CL})$.

( Uranyl acetate \& Lead citrate x 6300) 


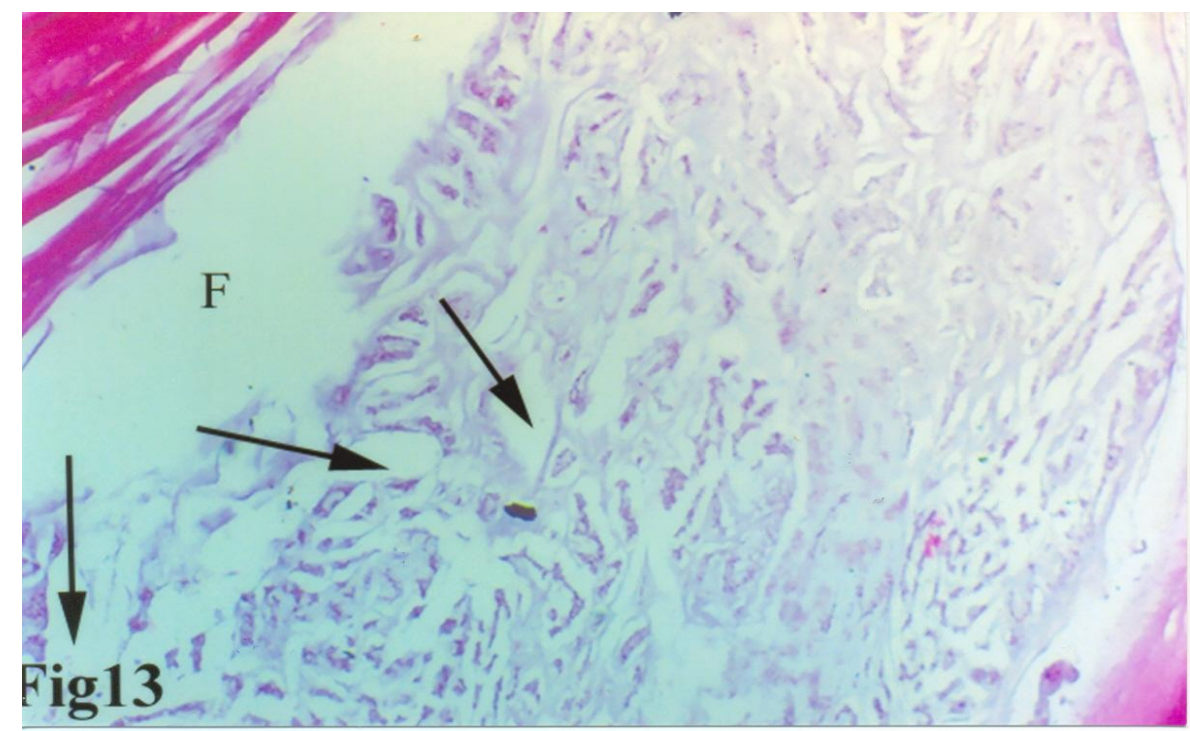

Fig (13): Photomicrograph of a section of intervertebral disc at lumbar region of eight weeks nicotine group (group 3), showing the progressive degeneration of the nucleus pulposus; the small spaces have expanded in many parts of the nucleus pulposus $(\rightarrow$ with wide separation from the adjacent annulus fibrosus $(F)$.

$($ H \& E x 100)

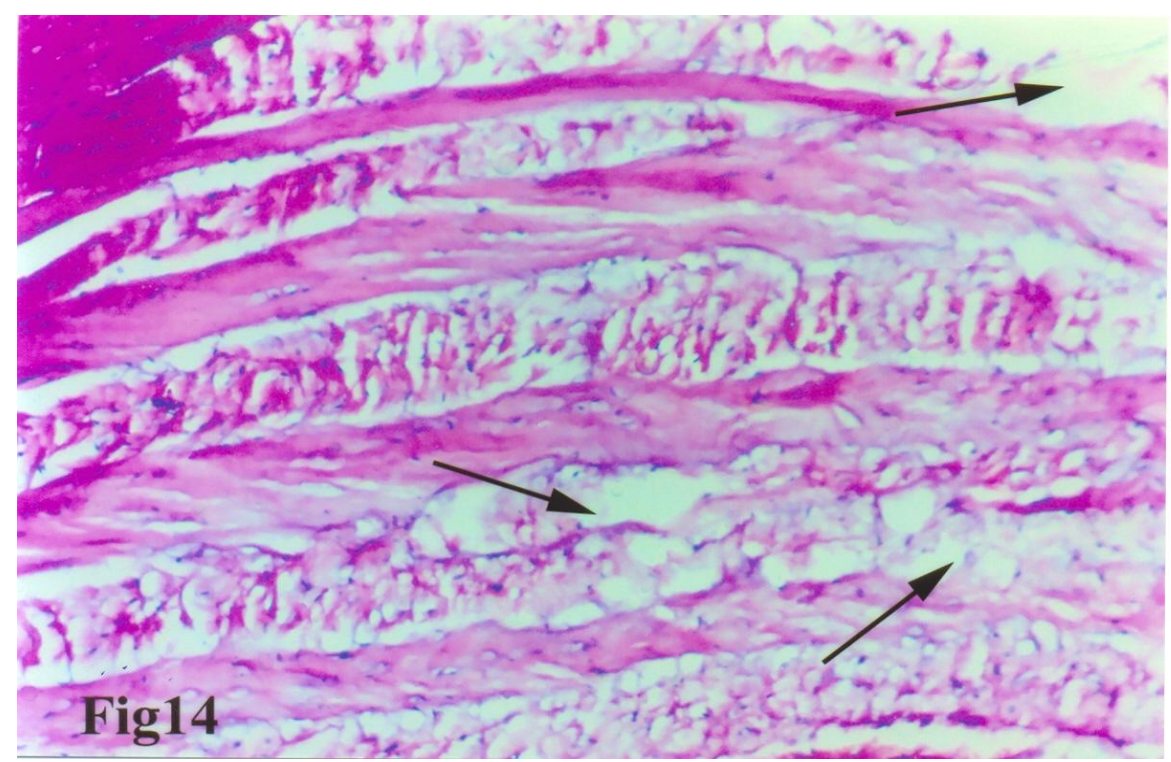

Fig (14): Photomicrograph of a section of intervertebral disc at lumbar region of eight weeks nicotine group (group 3), showing extensive irregularity of the multilayered structure of the annulus fibrosus $(\quad) . \rightarrow($ H \& E x 100) 


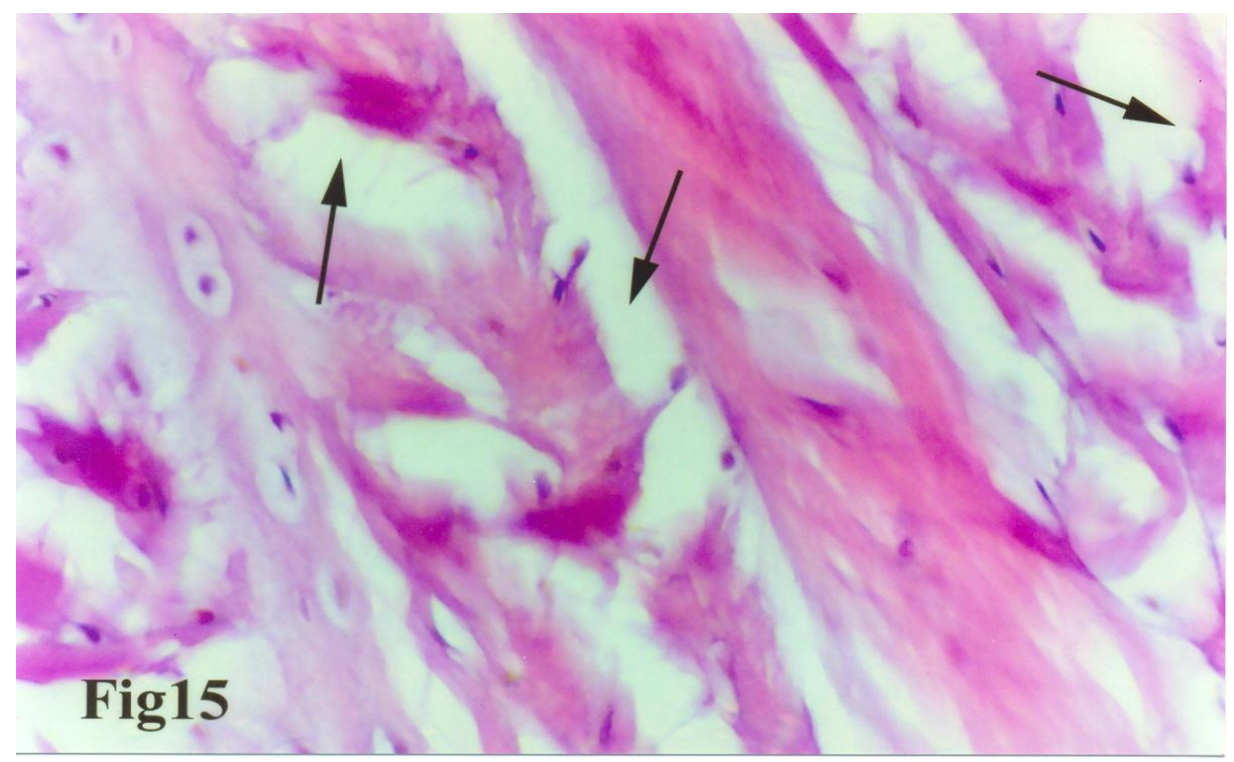

Fig (15): Photomicrograph of a section of intervertebral disc at lumbar region of eight weeks nicotine group (group 3), showing marked separation of the adjacent fibrous lamellae and appearance of wide cracks within the annulus fibrosus $(\stackrel{\rightarrow}{\rightarrow}$

( H \& E x 400)

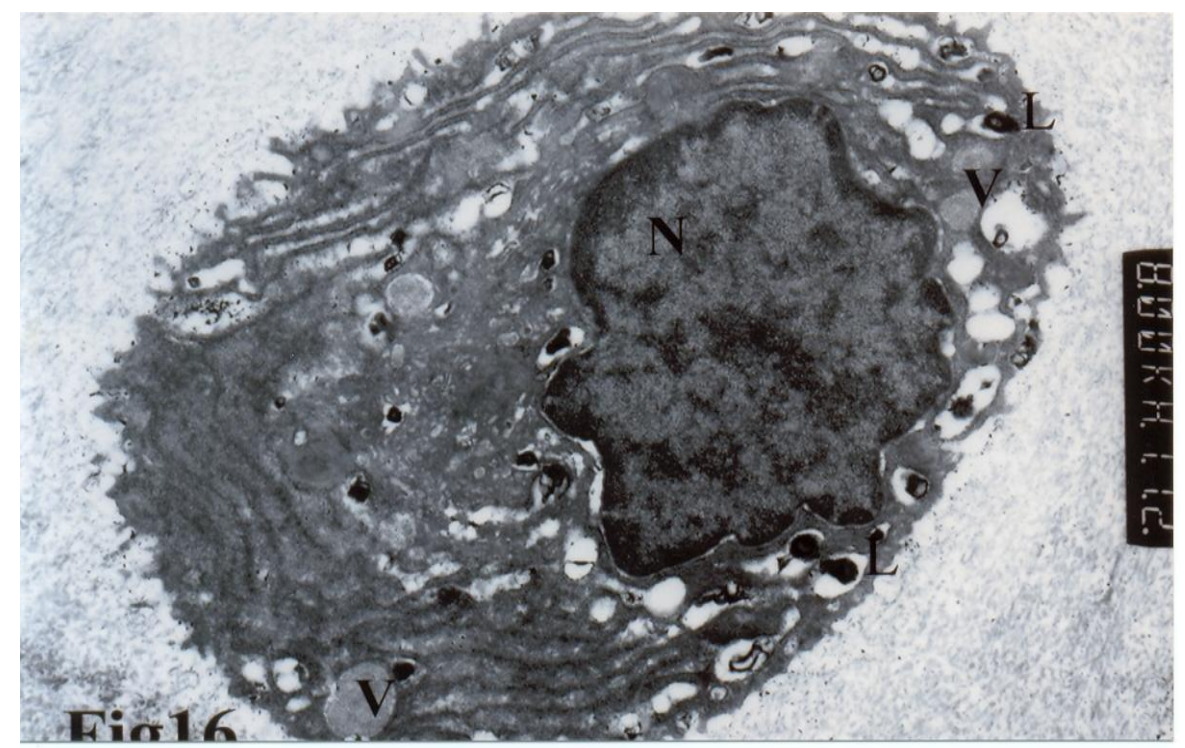

Fig (16): Electron micrograph of a section of intervertebral disc at lumbar region of eight weeks nicotine group (group 3), showing chondrocyte with extensive vacuoles (V) which contained many inclusion bodies (L). The nucleus appeared condensed with corrugated nuclear membrane $(\mathrm{N})$. (Uranyl acetate \& Lead citrate $\mathbf{x} 8000)$ 


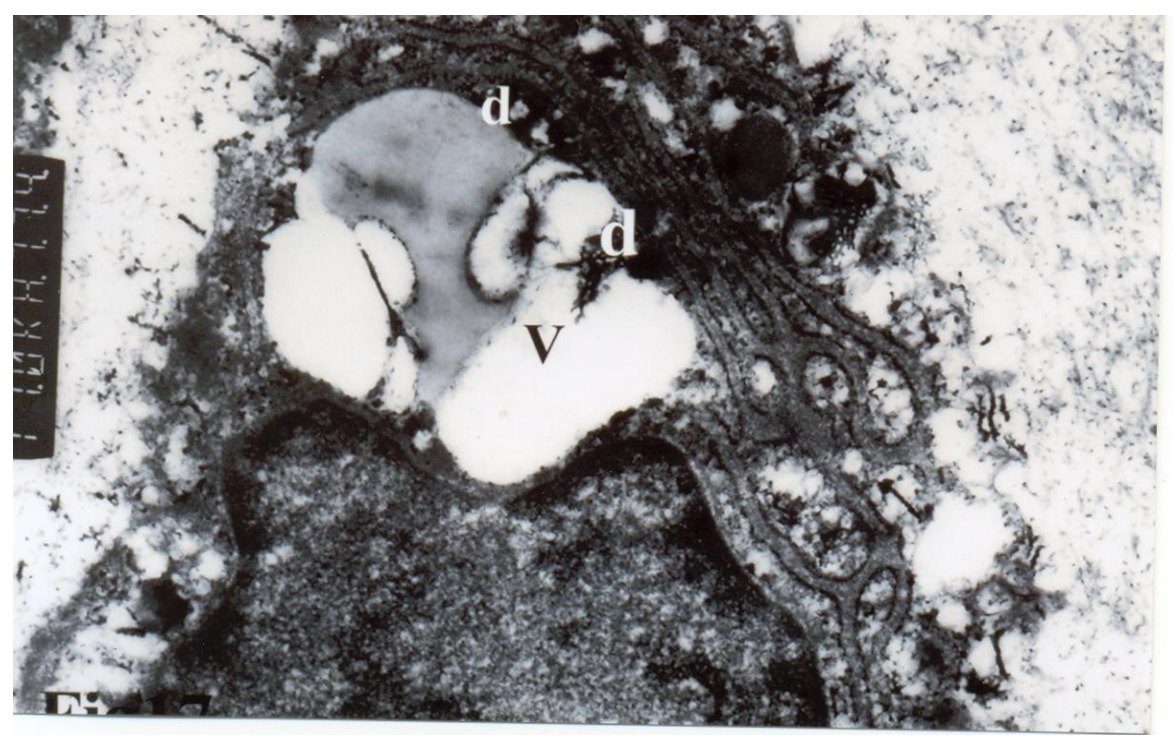

Fig (17): Electron micrograph of a section of intervertebral disc at lumbar region of eight weeks nicotine group (group 3), showing chondrocyte with large vacuole (V) which contained electron dense spots (d).

( Uranyl acetate \& Lead citrate $\mathbf{x}$ 17000)

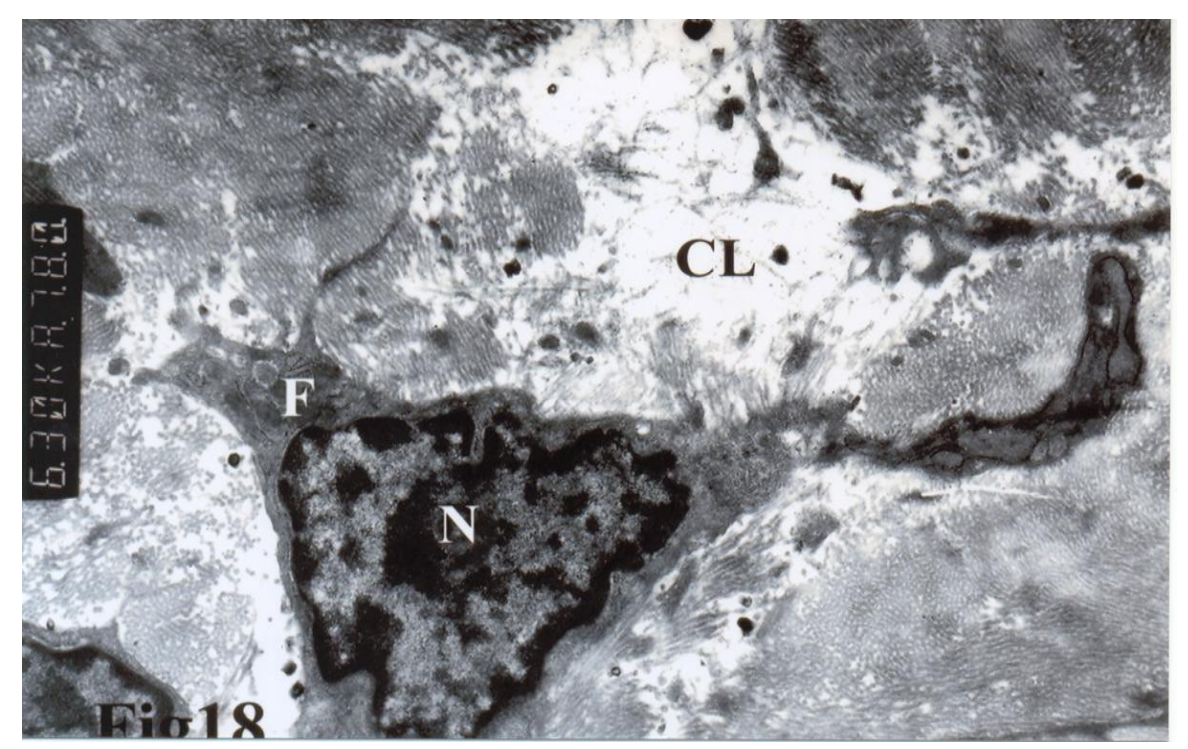

Fig (18): Electron micrograph of a section of intervertebral disc at lumbar region of eight weeks nicotine group (group 3), showing nucleus (N) of fibroblast (F) with corrugated nuclear membrane and there is extensive loss of the surrounding collagen fibers in the surrounding areas $(C L)$.

( Uranyl acetate \& Lead citrate $x$ 6300) 


\section{Discussion}

About 4000 substances are released when tobacco is burnt. These substances are in the form of either gas or particles. The major gaseous components of tobacco smoke include carbon monoxide, carbon dioxide, sulfur dioxide, cresol and amphenol. Whereas the particles include nicotine, tar and water (Uematsu et al., 2001).The separate effect of each component of tobacco on the intervertebral disc is not clear at the present. In this study examination of the effect of nicotine particles on the lumbar intervertebral discs of rabbits was done.

Examination of the annulus fibrosus of the control group revealed that, the outer surface of the chondrocyte appeared as ruffled appearance. These projections first appeared when cartilage matrix formation is initiated. Also the large amount of rER indicated that the cell is actively engaged in the production of cartilage matrix (Ross et al., 1995).

In this study discs in the nicotine groups showed a variety of histological changes, which were not observed in the control group. This includes appearance of spaces within the nucleus pulposus and separation from the adjacent fibrous lamellae of the annulus fibrosus. Also loss of the regularity of the multilayered structure of the annulus fibrosus, also, inclusion bodies and electron dense bodies associated with vacuoles within the chondrocytes suggesting that nicotine has negative effects on the discs by inducing degeneration of its parts. This agreed with Gruber \& Hanley (2002) who reported that such inclusions within the disc cells may possibly represent products retained in the cell and detected a problem with the product.

With regards to the effect of duration of treatment, disc degeneration was more marked in rabbits injected with nicotine for 8 weeks than in those injected for 4 weeks. Consequently, the severity of disc degeneration may correlate with the duration of smoking.

The intervertebral disc receive nutrients through two routes; the annular route, through which the disc receives blood directly from the vascular plexus surro-unding it, and the vertebral route, which supplies blood from the vertebral body through the vertebral endplate (Ogata and Whiteside 1981).

Histological study by Buckwalter (1995) on age related degeneration of the intervertebral disc showed that the degeneration commences around the vertebral endplate. Ogata and Whiteside (1981) reported that impairment and injury of the vascular bud system may be important cause of degeneration of the intervertebral disc, because the nutritional supply to the disc was hindered considerably when the vertebral route was interrupted. Stockwell (1983) speculated that the cells in the periphery could be aerobic because they are located near the source of oxygen. Therefore, it can be assumed that the fibro-blast cells, chondrocytes and notocordal cells indicate the degree of dependence on oxygen.

Nicotine is known to induce excitation of peripheral nerves in particular sympathetic and parasympathetic ganglia throughout body, as well as the central nervous system. Through this action, Uematsu et al., (2001) postulated that nicotine induced persistent vascular constriction around the intervertebral discs which might resulted in reduce cell activity in the intervertebral disc, leading to degeneration of tissue.

Holm and Nachems (1988) studied the acute effects of cigarette smoking on the intervertebral disc. Smoking was administered for 4-5 min. Using mechanical ventilation, in adult swine. Their results showed that smoking induced constriction of the capillary network surrounding the disc and a decrease in cell activity in the disc. Furthermore, Ishihara et al. (1994) also demonstrated that smoking reduced the volume of blood flow around the intervertebral disc, leading to a decrease in oxygen tension in the disc and changes in the energy generating system. This makes the disc incapable of synthesizing its constituents and vulnerable to degeneration. 
In habitual smokers, the number of white and red blood cells, hemoglobin concentration, and hematocrit value are increased (McGill 1971). In this regard, Ernst et al., (1987) postulated that the increased number of white blood cells in the peripheral circulation might obstruct small blood vessels, leading to a decrease in blood flow, with subsequent thrombosis followed by various vascular endothelial disorders.

Urban \& Roberts (1995) have reported that the exchange of materials between the external environment surrounding the intervertebral disc and the disc interior operated through two processes, diffusion and fluid follow. Diffusion was primary mechanism for the translocation of small size substances of low molecular weight. The molecular weight of nicotine (C10H14N2) was 162. Consequently, it can be transported into the disc rapidly by diffusion. Previous studies have also shown that nicotine is a cytotoxic agent (Fang et al.,1991). Consequently, degeneration of the disc may result from the cytotoxic effect.

Finallystt could be concluded that nicotine injection induced degeneration of the intervertebral disc and that disc degeneration was correlated with the duration of exposure to nicotine. Such an effect was probably due to a direct effect of nicotine, as well as an indirect effect through vasoconstriction of the vascular network surrounding the disc. Consequently further studies are necessary to prove the actual mechanism.

\section{References}

1. Abenhaim L,and Sussia $\mathbf{S}$ (1987): Impo-rtance and economic burden of occupat-ional back pain.J.Occup. Med.; 29:670-674.

2. Akmal M, Kesani A, Anand B and Singh A (2004): Effect of Nicotine on Spinal Disc Cells. Spine; 29(5): 568-575.

3. Antoniou $\mathbf{J}$, Steffen $\mathbf{T}$, and Nelson F, (1996): The human lumbar intervertebral disc. J Clin Invest; 98:996-1003.

4. Buckwalter J. (1995): Aging and dege-neration of the human intervertebral disc. Spine;20:13071314.

5. Ernst E, Hammerschmidt DG, and Bagge U. ( 1987):
Leucocytes and the risk of ischemic disorders. JAMA; 257:2318-2324.

6. Ernst E. (1994): Smoking , a cause of back trouble. Br J Rheum; 32: 239-242.

7. Fang MA, Frost PJ, and HadKlein A. (1991): Effects of nicotine on cellular function in UMR osteoblast like cells. Bone; 12:283-286.

8. Gruber H E, \& Hanley $\mathbf{E} \mathbf{N}$ (2002): Ultrastructure of the human intervertebral disc during aging and degeneration. Spine; 27(8): 798-805.

9. Holm $S$ and Nachems A (1988): Nutrition of the intervertebral disc: acute effects of cigarette smoking. Uppsala J Med Sci; 93:91-99.

10. Iatridis JC, Weidenbaum M., and Setton LA. (1996): Is the nucleus pulposis a solid or a fluid? Mechanical behaviour of the nucleus pulposis of the human intervertebral disc. Spine; 21:1174-1184.

11. Ishihara $\mathbf{H}$, Hirano $\mathbf{N}$ and Oshima H (1994): Effects of oxygen tension on cell metabolism and matrix synthesis in the intervertebral disc. Rin Sci Gai; 29:357-361.

12. Lawson GM., Hurt RD., and Dale LC. (1997): Application of serum nicotine and plasma nicotine concentrations to assessment of nicotine replacement in light, moderate, and heavy smokers. J Clin Pharm; 38:502-509.

13. McGill HC (1971): Smoking and leucocyte count. Results of an epidemi-ological survey. Lancent;18: 632-634.

14. Miller VM, Glucose WD, and Tonnessen BH (2000): Time and dose effect of transdermal nicotine on endothe-lial function. Am J Physiol Heart Circ; 279:1913-1921.

15. Ogata $k$, and Whiteside IA (1981): Nutrition pathway of the intervertebral disc. Spine; 6:211216.

16. Rang HP, Dale MM, and Rittern JM. And Moore PK. (2003): Drug dependence and drug abuse, Pharmacology, $5^{\text {th }}$ ed. P:648-654, Amison and Schuster company Churchill Livingstone.

17. Ross MH, Romrell LJ and Kaye GL (1995): Histology a Text and 
Atlas, $\quad 3^{\text {rd }} \quad$ ed. $\quad P: 188-187$. Lippincott William and Wilkins..

18. Scott SC, Goldberg MS, and Mayo NE (1999): The association between cigarette smoking and back pain in adults. Spine; 24:1090-1098.

19. Stockwell R A (1983): Cartilage. Vol. 1 Structure, function and biochemistry. Edited by KH brain. New York, Academic Press.253259.

\section{دراسة تجريبية عن تأثير النيكوتين على الغضاريف بين الفقرات}

تهلة ماهر عفيفى **\#ت و كوثر أحمد حافظ*

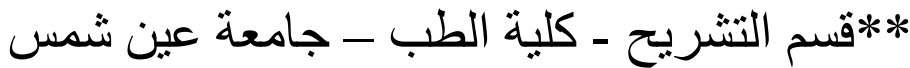

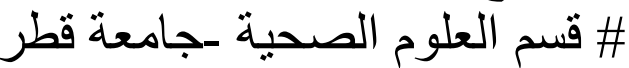

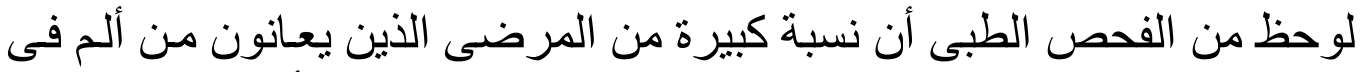

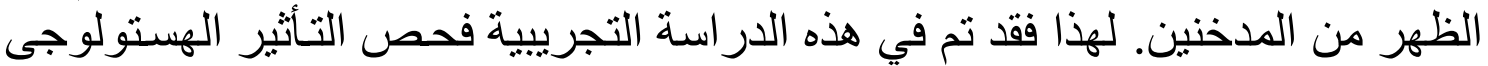

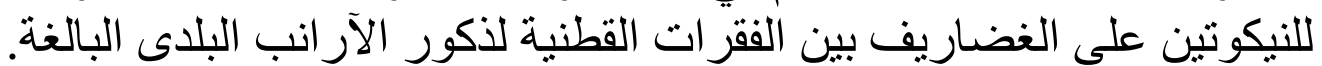

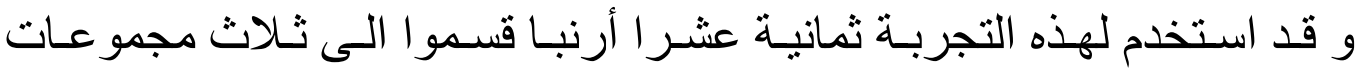

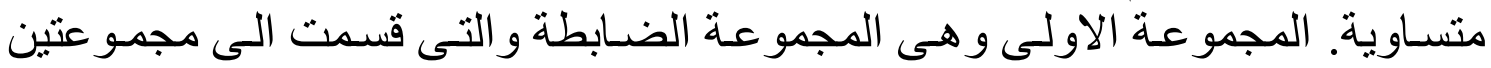
فر عيتين( أوبة).

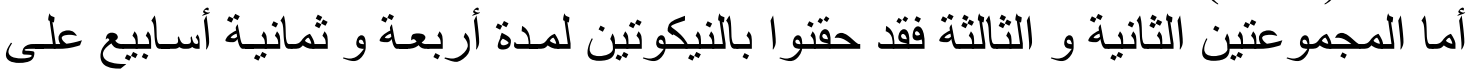

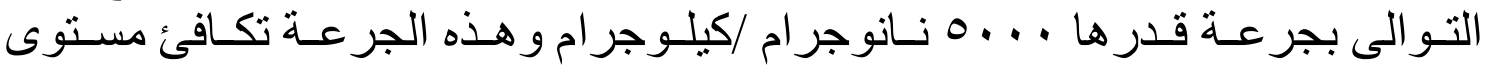

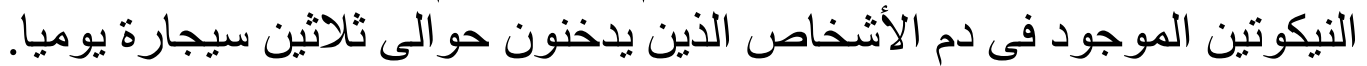

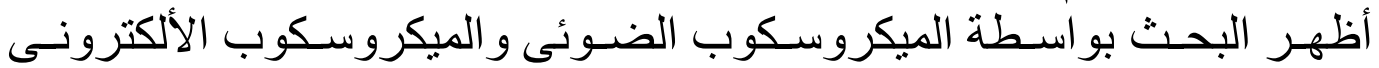

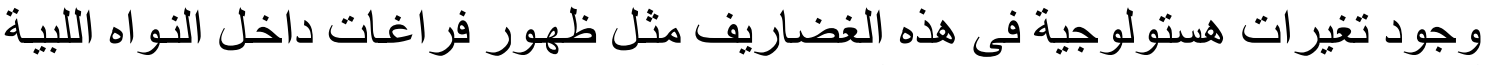

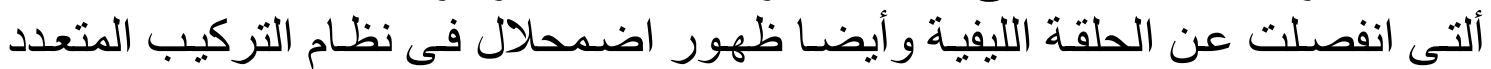
الطبقات للحلقة الليفية مع ظهور فر اغات متعددة داخل الخلايا الغضروفية.

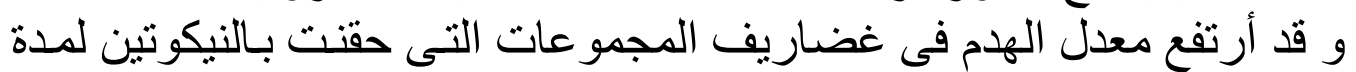

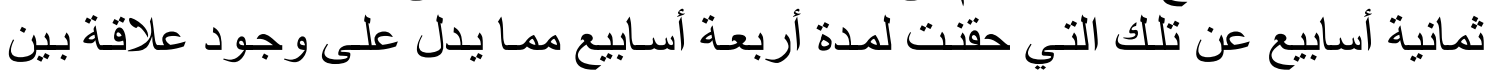

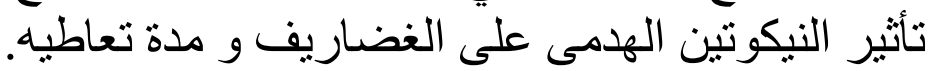

